\title{
Effects of Enoant and Ischemia and Reperfusion on Lens Metabolites of Rats
}

\author{
Hülya Güngel, ${ }^{1}$ Asiye Nurten, ${ }^{2}$ İhsan Kara, ${ }^{3}$ Serife Evrim Kepekci Tekkeli,, \\ Elif Özkök, ${ }^{3}$ and Burçin Yıldız
}

${ }^{1}$ Istanbul Training and Research Hospital, Clinic of Ophthalmology, Fatih, 34098 Istanbul, Turkey

${ }^{2}$ Department of Physiology, Faculty of Medicine, Yeni Yüzyll University, Topkapi, Istanbul, Turkey

${ }^{3}$ Istanbul University, Department of Neuroscience, Institute for Experimental Medicine, Istanbul, Turkey

${ }^{4}$ Department of Analytical Chemistry, Faculty of Pharmacy, Bezmialem Vakif University, Fatih, 34093 Istanbul, Turkey

${ }^{5}$ Faculty of Engineering and Natural Sciences, Sabancı University, Tuzla, Istanbul, Turkey

Correspondence should be addressed to Serife Evrim Kepekci Tekkeli; evrimkepekci@yahoo.com

Received 3 July 2013; Accepted 29 July 2013

Academic Editors: A. Garcia Asuero and C. Y. Panicker

Copyright @ 2013 Hülya Güngel et al. This is an open access article distributed under the Creative Commons Attribution License, which permits unrestricted use, distribution, and reproduction in any medium, provided the original work is properly cited.

\begin{abstract}
The effects of the ischemia and reperfusion on the lens metabolites and the effect of a phytotherapeutic commercial product called "Enoant" (mixed polyphenol content) on the selected lens metabolites were investigated. For this aim, 30 Wistar rats were divided into three groups according to their diet and being subjected to ischemia. 10 of the rats as Group I were fed on dry diet; the other 10 (Group II) were fed on dry diet and drinking water with Enoant. At the end of 15 days period, both groups of rats were subjected to ischemia for 2 hours and reperfused. After another 15 days with their same diet, the rats were decapitated. The remaining 10 rats, which were not subjected to ischemia (Group III), were fed on dry diet only. ${ }^{1} \mathrm{HNMR}$ spectroscopy was used for the determination of lens metabolites of each group of rats. The results obtained from the three groups have been compared statistically. The differences of metabolites were significant except pyruvate and succinate. Oral administration of Enoant revealed effects on increasing membrane stabilization, the antioxidant capacity, osmotic regulator molecule capacity, and sorbitol content of lens disturbed by ischemia. Enoant can be used where oxidative or osmotic stress is formed.
\end{abstract}

\section{Introduction}

As a necessity of life, the oxidative occurrences in cells cause the formation of reactive oxygen species (ROS) and are neutralized in lens through enzymatic or nonenzymatic means [1-3]. The insuffiencies in antioxidative systems induce production of several inflammatory proteins which contribute to the process of cells that promote damage to lipids, DNA, carbohydrates, and proteins.

ROS or free oxygen radicals stimulate cataract development. There are a large number of published items related to antioxidants that inhibit the development of cataract [4]. High plants contain flavones that adsorb free oxygen radicals and carry anti-inflammatory characteristics, and they also contain proanthocyanin and other polyphenolic compounds. Proanthocyanin have been reported to inhibit lipid peroxidation, platelet aggregation, and capillary permeability and fragility and to modulate the enzyme of systems including cyclooxygenase and lipoxygenase $[5,6]$. They may prevent free radical-mediated cytotoxicity and lipid peroxidation and protect low-density lipoproteins from oxidation [7]. Grape seed, grape juice, and wine are rich in these polyphenolic compounds. Resveratrol, quercetin, and catechin have recently been shown to have activity against oxidative stress. Flavones in the form of pure matter have been known to have apoptosis and the effect of stopping aging on the living tissue [8]. It has been shown that flavonols have an effect of decreasing sorbitol and increasing adenosine triphosphate (ATP) on diabetic rats. Flavonols carry out this effect by inhibiting aldose reductase that transforms glucose into sorbitol using nicotinamide adenine dinucleotide phosphate $(\mathrm{NADPH})$ as a cofactor. Aldose reductase (AR) has a role both in the development of cataract and the pathogenesis of neuropathy, nephropathy, and retinopathy complications 
[9-11]. Aldose reductase inhibitors (ARIs) have been studied in vivo to clarify their effectiveness in prevention of diabetic complications in experimental animals [12]. Besides, among the rats that were made diabetic with streptozotocin, it has been shown that while red wine reduces glucose, glycated hemoglobin $(\mathrm{HbAlC})$, and fructose in blood, it raises the level of insulin in blood [13]. The effects of polyphenols have been varied depending on concentration and synergy in grape extracts. Phenolic antioxidants carrying carboxyl and hydroxyl groups have affected the synergy with other polyphenols. These groups, in such a condition, cause a reduction in the ability of adsorbing free oxygen molecules; moreover, by causing cell necrosis, they may also have a raise in the number of free oxygen radicals [14].

Lens and cornea metabolites have been studied by means of nuclear magnetic resonance (NMR) spectroscopy since 1980s. Due to the easiness of their applicability, perchloric acid extracts have been studied on until recent years to define metabolites. In recent years, ${ }^{1}$ HNMR has been used more, especially in tumoral tissues, to follow the effect of apoptotic stimulations [15-18]. The most frequently studied marker of oxidative tissue damage is thiobarbituric reactive substance (TBARS), and the most frequently marker in the measurement of antioxidative capacity is reductant glutathione (GSH). We have aimed to research the effect on the lens metabolites caused by the application of ischemia/ reperfusion (I/R) and the effect on the selected lens metabolites caused by a commercial product called "Enoant," known to have high antioxidant characteristics because of the mixed polyphenol content and introduced as diet additive and a standardized concentrate of wine extract without alcohol.

\section{Material and Methods}

2.1. Investigation of Wine Extracts Concentrate. Enoant was kindly supplied by Te-ha Cosmetic Company (Istanbul, Turkey). The content of polyphenols in Enoant, extracted from skins and seeds of grape, was determined by high pressure liquid chromatography (HPLC) as $1.47 \mathrm{mg} / \mathrm{mL}$ catechin, $0.88 \mathrm{mg} / \mathrm{mL}$ epicatechin, $130 \mathrm{mg} / \mathrm{mL}$ quercetin, and $23 \mathrm{mg} / \mathrm{mL}$ resveratrol [19].

2.2. Investigation of Lenses. Preparation of animals was as follows: all animal studies are conducted according to the directives of the Environment European Commission (86/609/EEC). Wistar albino male rats $(n=30)$ weighing 200-250 g were used in this experiment. Animals were housed 3-4 rats per laboratory cages and maintained on $12 \mathrm{~h}$ light-dark cycle, with ad libitum access to standard laboratory conditions for at least 1 week prior to experiment. Ten of them were named as Group I, which were fed on dry diet. The other 10 rats (Group II) besides their diet received Enoant orally in fresh drinking water $(1.25 \mathrm{~g} / \mathrm{kg} /$ day $)$ for 15 days. At the end of the 15 days' period, the rats' bilateral carotids were tied up for 2 hours and ischemia was formed. Then, they were reperfused at the end of the 2 hours' period. The remaining 10 rats continued their dry diet only (Group III). These rats, which kept dieting for 15 days, were sacrificed with the application of peritoneal thiopental $(100 \mathrm{mg} / \mathrm{kg})$. The lenses of the 3 rats from each group were frozen to prepare perchloric acid extract. TBARS was maintained in one of the lenses of each of the remaining 7 rats, and reductant GSH was maintained in the other lenses. The ${ }^{1}$ HNMR spectra of the 3 rats were taken in perchloric acid extracts.

2.3. Preparation and Analysis of Perchloric Acid Extracts. The frozen lenses were pulverized with a porcelain mortar and pestle chilled with liquid nitrogen. Perchloric acid $(300 \mu \mathrm{L}$ $10 \%$ ) was added to tissue powder, and the powder was stirred continuously to a frozen paste consistency.

The frozen sample was immediately centrifuged at $3000 \mathrm{~g}$ for 10 minutes at room temperature. The supernatant was neutralized with $0.1 \mathrm{M}$ potassium hydroxide to $\mathrm{pH}$ values of 7.0-7.2. The sample was then centrifuged at $3000 \mathrm{~g}$ for 10 minutes at room temperature, and final supernatant was collected [20].

The prepared supernatants were dried under vacuum and were solved in $0.3 \mathrm{~mL}$ deuterium oxide (D20). The ${ }^{1}$ HNMR spectra were obtained with a Varian Unity Inova 500 spectrometer (11.7 T) operating $500 \mathrm{MHz}$ for protons.

Analysis of the spectra was performed with a special software which is used for analysis of complex mixtures. The data were reduced to a resolution of $0.6 \mathrm{~Hz} /$ point, omitting the spectral region downfield from $5.00 \mathrm{ppm}$ due to low signal-to-noise ratio. The spectra were assigned with the aid of these $1 \mathrm{D}$ experiments and by comparison with spectra of authentic compounds, together with reference to previous reports [21-30]. The most visible, assayable peaks in 0.5-5.00 ppm are sorbitol, scylloinositol (3.37 ppm, singlet), myoinositol, taurine, choline $(3.21,3.22$, and $3.23 \mathrm{ppm}$, singlets), and pyruvate/succinate (2.41 ppm, singlet). The peak for taurine, the $3.26 \mathrm{ppm}$ (triplet), was taken as reference instead of $3.41 \mathrm{ppm}$ (triplet). The region of $3.41 \mathrm{ppm}$ can clearly be seen through and because, $3.40 \mathrm{ppm}$ (triplet) B glucose, $3.41 \mathrm{ppm}$ (triplet) taurine, $3.42 \mathrm{ppm}$ (triplet) alpha glucose plus $3.45 \mathrm{ppm}$ (triplet) proline existed. For myoinositol (3.28 ppm, t; $3.56 \mathrm{ppm}, \mathrm{t}$ ), the peak $3.28 \mathrm{ppm}$ was taken as reference since they belong to glycine, myoinositol, glycerol and valine around the $3.56 \mathrm{ppm}$. Besides, in the literature scanning, it was learned that bisallic methylene fatty acyl which showed mobile fats and fat accumulation in the cell belonged to protons due to the apoptosis studies containing extraocular tissues of the $2.8 \mathrm{ppm}$ triplet that is quite distinctive in the lenses of the rats which were subjected to ischemia without Enoant [15]. The spectra were assigned with the aid of these experiments and spectra of authentic compounds together with reference to previous reports. In the literature, in the space between 3.60 and 3.90, mentioned as sorbitol region, there are superpose peaks belonging to the metabolites of threonine (3.60 ppm; d), myoinositol (3.63 ppm; dd), choline (3.66 ppm; $\mathrm{m}$ ), glutamine (3.68 ppm; $\mathrm{t})$, leucine (3.69 ppm; dd), and serine (3.84 ppm; dd).

Additionally, a large number of superpose peaks that belong to glucose, fructose, and sorbitol in the space between 3.00 and $5.00 \mathrm{ppm}$. That is why the triplet in the space between 3.71 and $3.74 \mathrm{ppm}$ for sorbitol was taken as reference. In addition to this, in the literature, the triplet 3.73 was 
reported to have risen in the shortage of sorbitol dehydrogenase [31]. The relative integrals of the reference peaks of the selected metabolites in the space between 0.5 and $5.00 \mathrm{ppm}$ were taken considering the water, since the water was put fixedly in the ${ }^{1}$ HNMR preparation of Group I, II, and III. And the average relative integral results among each 3 groups were compared statistically.

2.4. Measurement of GSH Levels of Lenses. Deproteinase solution (120 g NaCl, $6.68 \mathrm{~g}$ m-phosphoric acid, and $0.8 \mathrm{~g}$ EDTA) were added to $10 \%$ tissue homogenate of lens. Precipitated proteins were removed by centrifugation. $0.6 \mathrm{M}$ disodium phosphate and 5,5'-dithio-bis-2-nitrobenzoic acid (DTNB) as reagent were added to the supernatant, and the samples were measured at $412 \mathrm{~nm}$ within 5 minutes. The results were expressed as $\mu \mathrm{moL} / \mathrm{g}$ tissue [32].

2.5. Measurement of TBARS Levels of Lenses. $10 \%$ lens homogenate were prepared with $0.15 \mathrm{M} \mathrm{KCL}$. $50 \mu \mathrm{L} 8.1 \%$ sodium dodecyl sulfate, $50 \mu \mathrm{L}$ acetic acid (adjusted to $\mathrm{pH} 3.5$ ) and $100 \mu \mathrm{L}$ thiobarbituric acid (TBA) reagents were added to $50 \mu \mathrm{L}$ homogenate. The reaction mixture was kept in a boiling water bath for 45 minutes. After cooling to room temperature, TBA was extracted with $\mathrm{n}$-butanol/pyridine $(15: 1)$. The samples were measured at $535 \mathrm{~nm}$. The results were calculated as $\mathrm{nmoL} / \mathrm{g}$ tissue [33].

2.6. Statistics. The relative integrals of the selected lens metabolites and GSH levels and oxidation levels of the lipids (TBARS) of Wistar rats that experienced I/R (Group I and II) and control group (Group III) were compared statistically between Group I and II and between Group II and III. The effect of the I/R on the lens metabolites and the effect of Enoant on the changings in Group I and Group II and Group II from Group III were compared statistically and discussed by the literature. The differences between the density averages of the metabolites were compared by "Mann Whitney $U$ " test. Data were expressed as mean \pm SD. $P<0.05$ was accepted to be statistically significant for all results.

\section{Results and Discussion}

3.1. The Results of ${ }^{1}$ HNMR Analysis of Perchloric Acid Extracted Lenses. In the literature, nearly 25 metabolites can be found in these spectra, including valine, leucine/isoleucine, 3-OH butyrate, threonine, lactate, alanine, acetate, lisin, $\mathrm{N}$-acetylglucosamine, glutamate, glutathione, pyruvate/succinate, glutamine, citrate, glucose, hypotaurine, aspartate, choline and its derivatives (phosphocholine, glycerophosphocholine), taurine, myoinositol, scylloinositol, glisin, sorbitol, sorbitol 3 phosphate, and serine peaks. But the most visible, assayable peaks are in 0.5-5.00 ppm, which are sorbitol derivatives, scylloinositol, myoinositol, taurine, phosphocholine, pyruvate/succinate, acetone, acetate, and the triplet at $2.8 \mathrm{ppm}$.

Sample spectra in the space between 0.5 and $5.00 \mathrm{ppm}$ of Group I, II, and III was shown in Figure 1. Integral spaces were marked after expanded spectra for each metabolite.
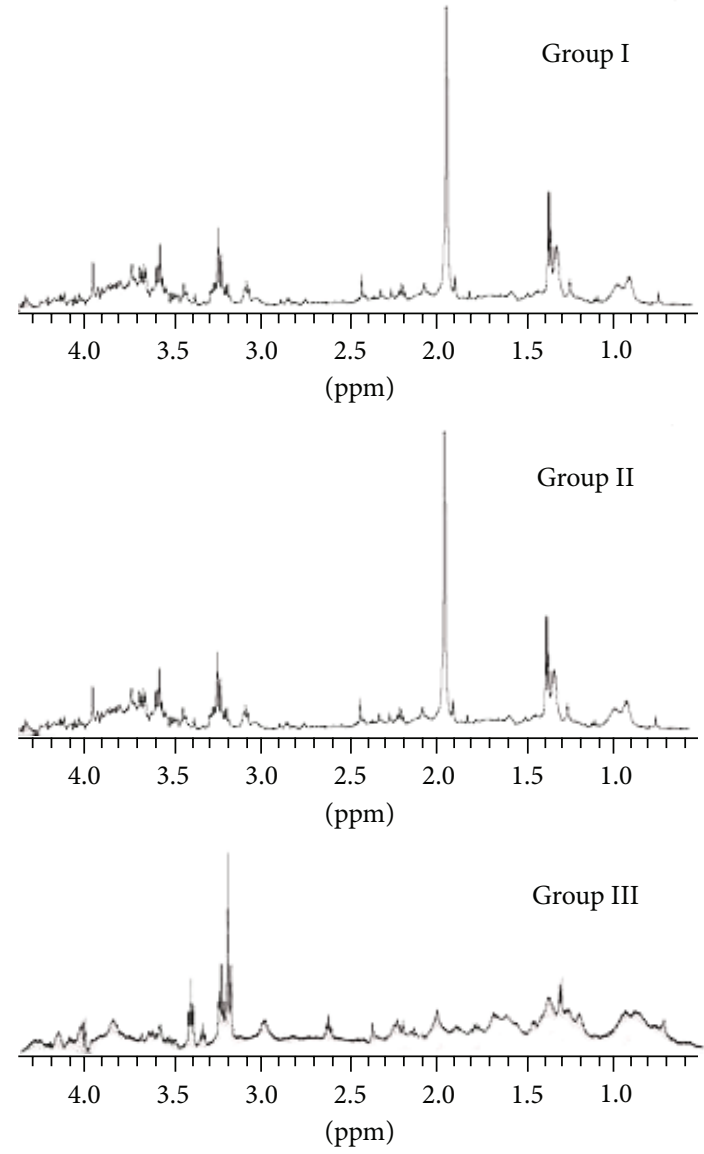

Figure 1: ${ }^{1} \mathrm{HNMR}$ spectroscopy of metabolites of lenses between 0.5 and $4.5 \mathrm{ppm}$.

Sorbitol (3.71-3.75 ppm), scilloinositol (3.38-3.36 ppm), myoinositol (3.29-3.27 ppm), taurin (3.264-3.25 ppm), choline $(3.22-3.20 \mathrm{ppm})$, pyruvate/succinate $(2.42-2.40$ ppm), acetone (2.32-2315 ppm), acetate (1.965-1.90 ppm), and a triplet at $2.8 \mathrm{ppm}$ was observed clearly. The triplet at $2.8 \mathrm{ppm}$ in Group III could not be seen. Pyruvate/succinate peak had the same relative integral density in all groups.

The average relative integral density rates of clear, observable, and measurable metabolites in groups were shown in Figure 2.

The differences between the density averages of the metabolites of Groups I and II, except for pyruvate/succinate $(P=1.0)$ and scylloinositol $(P=1.0)$ and for taurine $(P=0.043)$ and acetate $(P=0.03)$, were severely significant statistically $(P<0.003)$. The differences between all metabolites of Groups II and III were severely significant statistically $(P=0.003)$ except pyruvate/succinate $(P=1.0)$.

3.2. TBARS Rates of Lenses. While TBARS rate in Group III was $1.08 \pm 0.04 \mathrm{nmoL} / \mathrm{g}$ lens in average and in Group II $4.10 \pm$ $0.08 \mathrm{nmoL} / \mathrm{g}$ lens wet weight, it was determined as $18.62 \pm$ $0.12 \mathrm{nmoL} / \mathrm{g}$ lens wet weight in Group I. The difference (between Group I and II and the difference between Group II and III) was statistically significant $(P<0.001)$. 


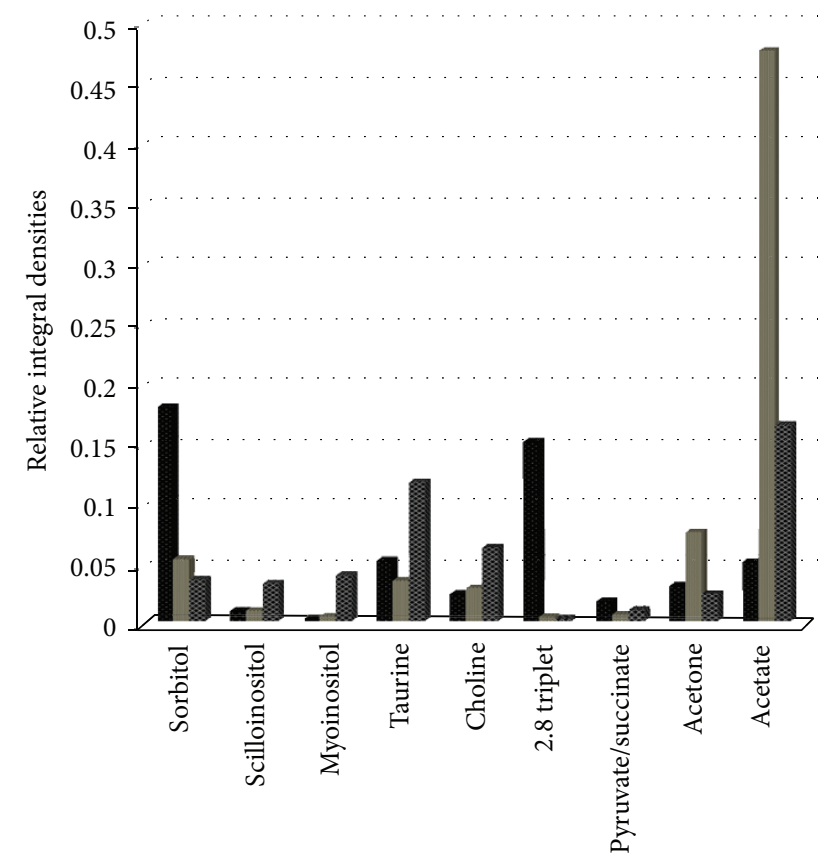

- GROUP I

If GROUP II

- GROUP III

FIgURE 2: The averages of lens metabolites in the study groups.

3.3. Reduced GSH Rates of Lenses. The average GSH rates of lenses in Group III were calculated as $15.6 \pm 0.95 \mu \mathrm{moL} / \mathrm{g}$ lens wet weight, $9.02 \pm 0.72 \mu \mathrm{moL} / \mathrm{g}$ lens wet weight in Group II, and $2.41 \pm 0.13 \mu \mathrm{moL} /$ glens wet weight in Group I. The difference between Group I and Group II and Group II and Group III was statically significant $(P<0.001)$.

${ }^{1} \mathrm{HNMR}$ analysis makes it possible to observe lots of metabolites. Most metabolites are largely caused by humor aqueous and others are synthesized in lenses. Studies that focused on the interaction of the lens metabolites, caused by several chemicals, are going on. The effects of grapefruit seed extract (GSE) on aging and diabetes have been investigated [34].

The singlets in $3.21,3.22$, and 3.23 ppm have been known to belong to their derivatives with choline and phosphate [21, 25 ]. The tasks of cholines in lenses have not yet been exactly clarified; they have been known to have a task of carrying in the cell membrane.

It was reported that there was a decrease in the number of choline metabolites (phosphocholine at $3.21 \mathrm{ppm}$ ) in a study of apoptosis with radiation stimulation, whereas, in another study, cholines were reported not to be effected from apoptosis at all. Again in the followup of apoptotic response in extraocular tissues, ${ }^{1} \mathrm{HNMR}$ studies carried out with reasons like separation from necrosis, $\mathrm{CH}_{2}$ peak, which was $1.3 \mathrm{ppm}$ membrane lipid resonance of the triplet in $2.8 \mathrm{ppm}$ belonging to bisallic methylene fatty acyl protons, were stated to increase, and the ratio of $\mathrm{CH}_{2} / \mathrm{CH}_{3}$ depending on the volume of the apoptosis was also indicated to increase $[15,16,19]$. The lipid peaks observed in ${ }^{1}$ HNMR are terminal methyl (0.8$1.0 \mathrm{ppm}$ ), acyl chain methylene (1.1-1.5 ppm), alpha- and betamethylene (2.0-2.5 ppm), and olefinic protons (5.4 ppm). In an apoptosis study developing after a muscle burnt, it was mentioned that $2.8 \mathrm{ppm}$ lipid peak increased, but acyl chain methylene and terminal peaks decreased [15]. In this study, when the difference of $3.21 \mathrm{ppm}$ peak between the groups is investigated, there is a significant difference between Groups I and II lenses, where ischemia/reperfusion was applied, for the benefit of Group II. However, the average $3.21 \mathrm{ppm}$ peak of Group III lenses is far more than both groups. While $2.8 \mathrm{ppm}$ triplet was observed in Group I lenses, this peak was not observed clearly in the other two groups. In our studies of cornea and lens ${ }^{1} \mathrm{HNMR}$ that we took as a reference, $2.8 \mathrm{ppm}$ triplet was not mentioned. Without taking mixed polyphenol content, $2.8 \mathrm{ppm}(\mathrm{t})$ in the lenses of the living rats and the rats that had I/R was applied to be one of the major peaks. This study shows that saturated fats could increase in lenses among the rats that lived 2 hours of I/R. Dieting with Enoant, though it fails to succeed to maintain a normal lens level after I/R, seems to protect the lenses of Wistar rats from lipid accumulation in the cell.

It was shown that quercetin, an element of GSE, supplied its antioxidant effect by not only catching the free radicals, but also protecting the cell from free radicals by directly combining with $\mathrm{H}_{2} \mathrm{O}_{2}$. It was informed that quercetin inhibits the access of $\mathrm{Ca}^{+2}$ and $\mathrm{Na}^{+}$ions caused by $\mathrm{H}_{2} \mathrm{O}_{2}$ into the cell; besides, the protection against the $\mathrm{H}_{2} \mathrm{O}_{2}$ cataract was also provided with the protection of membrane canal proteins by means of phenolics in GSE [35].

When $\mathrm{H}_{2} \mathrm{O}_{2}$ increases in the cell, nicotinamide adenine dinucleotide (NAD), GSH, ATP, and lactate decrease $[36,37]$. When $\mathrm{H}_{2} \mathrm{O}_{2}$ increases, membranes of the cell are damaged and its cytoskeleton is destroyed, and polyADP ribose polymerase activates and breaks up NAD; besides, high content of $\mathrm{H}_{2} \mathrm{O}_{2}$ causes damage to crystallines by formation of proteins with low solubility due to the fact that it causes the formation of new fluorophors [38]. It has been claimed that proanthocyanidines existing in GSEs inhibit cataract development by increasing the antioxidative capacity of lenses. In the literature, it was shown that the loss of oxide glutathione in cataracts, oxidation of membrane lipids, oxidation of protein thiols, formation of cysteic acid, methionine sulphoxide, mixed disulfides, and protein disulfides were formed [39].

In this study, the fact that the reductant glutathione decreased and the rate of TBARS was significantly high in Group I lenses, when compared to Group II and Group III lenses, proved that the oxidative stress existed in Group I and seemed to promote the rise of $\mathrm{H}_{2} \mathrm{O}_{2}$ in the cell. GSH is present in relatively high concentrations in the lens and is involved in protection from oxidative damage, amino acid, and cation transport across the cell membrane [40, 41]. Orally intaking of Enoant, which is a wine extract, following I/R increased antioxidative capacity in Group II. The fact that the MDA level of Group II was lower than that of Group I shows that that the antioxidative capacity of the lens increased and it is compatible with the literature. We consider that Enoant in diets protects lenses from oxidative stress and is 
likely to provide a better liquid-electrolyte access control with the supply of membrane stabilization and a better barrier function. But intaking of Enoant in I/R groups could not be sufficient for GSH and TBARS rates to reach normal lens levels.

Taurine begins to accumulate when lens is developing and there is $66 \%$ moL taurine in two-month-old rats [42]. Taurine uptake in the lens is slow, and this reminds of endogen taurine synthesizer mechanism [39]. Taurine is osmoregulator, ion regulator, and membrane stabilizer. It was shown that the decrease of taurine in diabetics was formed for osmotic balance needed as a result of the accumulation of sorbitol in the lens and a loss of taurine and other amino acids in lenses incubated with high glucose occurred. Taurine is an amino acid with antioxidant feature and its existence that causes an increase in the antioxidant potentials of other amino acids was informed [43]. Taurine is a general prophylactic and capturer against reactive oxygen species. Taurine is protective against the damage of superoxides and inhibits the formation of hydroxyls from superoxides by capturing superoxides more than hydroxyl radicals $[42,44]$. The decrease of taurine causes the formation of sorbitol, in other words, it inhibits autoxidation [45]. Taurine is an antioxidant as important as vitamin C in humans. In this study, taurine in Group III lenses is dramatically higher than those of both Group I and Group II. That sorbitol is low in Group III is also appropriate for the literature. Diet with Enoant in Group II after I/R made taurine higher in Group I. According to Group I cases, that the rate of taurine is high matches the fact that the sorbitol is again appropriate for the literature.

It is reported that inositol has also a similar effect [46, 47]. Between the scilloinositol rates in Groups I and II, not a significant difference has been observed. Scilloinositol in Group III lenses that have not experienced I/R is higher than Groups I and II dramatically. Myoinositol itself is at the highest rate in Group III; it has higher rates in Group II than in Group I. It was shown that the addition of ARIs inhibited the development of diabetic cataract among the rats fed on galactose and in investigations; it increased the level of myoinositol in the lens [48]. It was also shown that ARIs decreased the outgoing/releasing of myoinositol in the cell. The loss of myoinositol also decreased when lenses were put in a hypotonic environment. It is claimed that anionic canal and/or carrier-mediated transport protein helps myoinositol go out of the cell [37]. It was shown that myoinositol decreased the oxidizing features of peroxides in the cell depending on the dose [49]. It was shown that myoinositol accumulated in the lens epithelium with the aim of adaptation to hypertonicity [50]. It is claimed that the activity increase of the enzyme of Na-K ATPase makes it easier for organic osmolites like taurine and myoinositol to accumulate in the face of hypertonic stress [51].

In this study it did not become possible for us to show whether there was hypertonicity in the lens, depending on the existence of polyphenols that probably passed to lens or anterior chamber. In this study, it is just not possible to say whether this occurs depending on the effect of osmotic shock formed from the increase of both taurine and myoinositol or the effect of sorbitol whose development was inhibited in glucose metabolism or the decrease of myoinositol outgoing/releasing with/by ARI effect. The diet with Enoant in cases that had I/R seems to be an assistant agent on protecting the taurine and myoinositol content of the lens. In a series of investigations, a number of flavonoids compounds, isolated from plants were characterized as aldose reductase inhibitors [52]. For taurine and myoinositol to be higher and for sorbitol in the lenses of Group II rats related to flavonoids contained by Enoant to be lower dramatically were accomplished.

What is the significant finding in this investigation is that pyruvate/succinate peak in $2.41 \mathrm{ppm}$ is similar in each of the three groups. In case of maintaining normal diet, I/R or intake of Enoant did not have an effect on the level of pyruvate which is synthesized as a first step in glycolysis.

The differences between acetone and acetate relative integral rates among the groups are also statistically important, but we were not able to explain the metabolic importance of these differences for lenses.

Lactate seems as a doublet at $1.32 \mathrm{ppm}$ in ${ }^{1} \mathrm{HNMR}$ spectroscopy. Because this region is $-\mathrm{CH}_{2}$ region, it was very noisy, and lactate could not be determined clearly. The limitation of this study was that lactic acid could not be determined by relevant integral densities in NMR spectroscopy.

As a result, it was shown that for Enoant, a commercial product, which contains polyphenol and flavonoids complexes, to be used orally, had an effect on increasing membrane stabilization, the antioxidant capacity of lens, osmotic regulator molecule capacity, and sorbitol content after I/R. Enoant could be used in natural or special cases, where oxidative or osmotic stress was formed, with the purpose of inhibiting complications like especially diabetic cataract and neuropathy, as a protective or perhaps curative remedy in cases such as UV, which stimulates oxidant or several apoptotic responses, or perhaps with the aim of helping treatment as a supplementary product, and in this direction it was convinced that studies supported by histological inspections need to be planned.

\section{Acknowledgments}

The authors thank Professor Dr. Atilla Güngör, Ph.D., Marmara University, Faculty of Chemistry, for guidance and Professor Dr. Gülaçtı Topçu, Bezmialem Vakif University, Faculty of Pharmacy, for analyzing of ${ }^{1} \mathrm{HNMR}$ and ${ }^{13} \mathrm{CNMR}$ spectroscopies.

\section{References}

[1] K. Bhat, "Scavenging of peroxide and related oxidants in human brunecent cataracts," in Ocular Pharmacology. Recent Advances, S. K. Gupta, Ed., pp. 32-83, Indian Ocular Pharmacological Society, New Delhi, India, 1991.

[2] A. Spector, "Oxidative stress-induced cataract: mechanism of action,” FASEB Journal, vol. 9, no. 12, pp. 1173-1182, 1995.

[3] S. D. Varma, P. S. Devamanoharan, and S. M. Morris, "Prevention of cataracts by nutritional and metabolic antioxidants," Critical Reviews in Food Science and Nutrition, vol. 35, no. 1-2, pp. 111-129, 1995. 
[4] P. F. Jacques and L. T. Chylack Jr., "Epidemiologic evidence of a role for the antioxidant vitamins and carotenoids in cataract prevention," American Journal of Clinical Nutrition, vol. 53, no. 1, pp. 352-355, 1991.

[5] W. Bors and M. Saran, "Radical scavenging by flavonoid antioxidants," Free Radical Research Communications, vol. 2, no. 4-6, pp. 289-294, 1987.

[6] H. Kolodziej, C. Haberland, H. J. Woerdenbag, and A. W. T. Konings, "Moderate cytotoxicity of proanthocyanidins to human tumour cell lines," Phytotherapy Research, vol. 9, no. 6, pp. 410-415, 1995.

[7] E. N. Frankel, J. Kanner, J. B. German, E. Parks, and J. E. Kinsella, "Inhibition of oxidation of human low-density lipoprotein by phenolic substances in red wine," Lancet, vol. 341, no. 8843, pp. 454-457, 1993.

[8] D. Bagchi, A. Garg, R. L. Krohn et al., "Protective effects of grape seed proanthocyanidins and selected antioxidants against TPA-induced hepatic and brain lipid peroxidation and DNA fragmentation, and peritoneal macrophage activation in mice," General Pharmacology, vol. 30, no. 5, pp. 771-776, 1998.

[9] D. J. Handelsman and J. R. Turtle, "Clinical trial of an aldose reductase inhibitor in diabetic neuropathy," Diabetes, vol. 30, no. 6 , pp. $459-464,1981$.

[10] Y. S. Lee, S. Lee, H. S. Lee, B.-K. Kim, K. Ohuchi, and K. H. Shin, "Inhibitory effects of isorhamnetin-3-O- $\beta$-D-glucoside from salicornia herbacea on rat lens aldose reductase and sorbitol accumulation in streptozotocin-induced diabetic rat tissues," Biological and Pharmaceutical Bulletin, vol. 28, no. 5, pp. 916918, 2005.

[11] S. S. Lim, S. H. Jung, J. Ji, K. H. Shin, and S. R. Keum, "Synthesis of flavonoids and their effects on aldose reductase and sorbitol accumulation in streptozotocin-induced diabetic rat tissues," Journal of Pharmacy and Pharmacology, vol. 53, no. 5, pp. 653668, 2001.

[12] A. Beyer-Mears, E. Cruz, and E. Varagiannis, "Reversal of stageI sugar cataract by Sorbinil, an aldose reductase inhibitor," Pharmacology, vol. 31, no. 2, pp. 88-96, 1985.

[13] P. Montilla, M. Barcos, M. C. Muñoz, J. R. Muñoz-Castañeda, I. Bujalance, and I. Túnez, "Protective effect of MontillaMoriles appellation red wine on oxidative stress induced by streptozotocin in the rat," Journal of Nutritional Biochemistry, vol. 15, no. 11, pp. 688-693, 2004.

[14] A. Sugisawa, S. Inoue, and K. Umegaki, "Grape seed extract prevents $\mathrm{H}_{2} \mathrm{O}_{2}$-induced chromosomal damage in human lymphoblastoid cells," Biological and Pharmaceutical Bulletin, vol. 27, no. 9, pp. 1459-1461, 2004.

[15] L. G. Astrakas, I. Goljer, S. Yasuhara et al., "Proton NMR spectroscopy shows lipids accumulate in skeletal muscle in response to burn trauma-induced apoptosis," FASEB Journal, vol. 19, no. 11, pp. 1431-1440, 2005.

[16] T. Bezabeh, M. R. A. Mowat, L. Jarolim, A. H. Greenberg, and I. C. P. Smith, "Detection of drug-induced apoptosis and necrosis in human cervical carcinoma cells using ${ }^{1} \mathrm{H}$ NMR spectroscopy," Cell Death and Differentiation, vol. 8, no. 3, pp. 219-224, 2001.

[17] F. G. Blankenberg, P. D. Katsikis, R. W. Storrs et al., "Quantitative analysis of apoptotic cell death using proton nuclear magnetic resonance spectroscopy," Blood, vol. 89, no. 10, pp. 37783786, 1997.

[18] V. M. Mikhailenko, A. A. Philchenkov, and M. P. Zavelevich, "Analysis of ${ }^{1} \mathrm{H}$ NMR-detectable mobile lipid domains for assessment of apoptosis induced by inhibitors of DNA synthesis and replication," Cell Biology International, vol. 29, no. 1, pp. 3339, 2005.

[19] I. Kara, A. Nurten, M. Aydın et al., "Ischemia/reperfusion in rat: antioxidative effects of enoant on EEG, oxidative stress and inflammation," Brain Injury, vol. 25, no. 1, pp. 113-126, 2011.

[20] Ø. Risa, O. Sæther, A. Midelfart, J. Krane, and J. Čejková, "Analysis of immediate changes of water-soluble metabolites in alkali-burned rabbit cornea, aqueous humor and lens by highresolution 1H-NMR spectroscopy," Graefe's Archive for Clinical and Experimental Ophthalmology, vol. 240, no. 1, pp. 49-55, 2002.

[21] W. T. Evanochko, T. T. Sakai, T. C. Ng et al., "NMR study of in vivo RIF-1 tumors. Analysis of perchloric acid extracts and identification of $1 \mathrm{H}, 31 \mathrm{P}$ and $13 \mathrm{C}$ resonances," Biochimica et Biophysica Acta, vol. 805, no. 1, pp. 104-116, 1984.

[22] M. Fris, J. Čejková, and A. Midelfart, "Changes in aqueous humour following single or repeated UVB irradiation of rabbit cornea," Graefe's Archive for Clinical and Experimental Ophthalmology, vol. 245, no. 11, pp. 1705-1711, 2007.

[23] I. S. Gribbestad and A. Midelfart, "High-resolution ${ }^{1} \mathrm{H}$ NMR spectroscopy of aqueous humour from rabbits," Graefe's Archive for Clinical and Experimental Ophthalmology, vol. 232, no. 8, pp. 494-498, 1994.

[24] I. S. Gribbestad, S. B. Petersen, H. E. Fjosne, S. Kvinnsland, and J. Krane, "1 H NMR spectroscopic characterization of perchloric acid extracts from breast carcinomas and non-involved breast tissue," NMR in Biomedicine, vol. 7, no. 4, pp. 181-194, 1994.

[25] A. Midelfart, A. Dybdahl, and I. S. Gribbestad, "Metabolic analysis of the rabbit cornea by proton nuclear magnetic resonance spectroscopy," Ophthalmic Research, vol. 28, no. 5, pp. 319-329, 1996.

[26] J. K. Nicholson, P. J. D. Foxall, M. Spraul, R. D. Farrant, and J. C. Lindon, "750 MHz $1 \mathrm{H}$ and $1 \mathrm{H} 13 \mathrm{C} \mathrm{NMR} \mathrm{spectroscopy} \mathrm{of}$ human blood plasma," Analytical Chemistry, vol. 67, no. 5, pp. 793-811, 1995.

[27] N. Pescosolido, A. Miccheli, C. Manetti, G. D. Iannetti, J. Feher, and C. Cavallotti, "Metabolic changes in rabbit lens induced by treatment with dexamethasone," Ophthalmic Research, vol. 33, no. 2, pp. 68-74, 2001.

[28] Ø. Risa, Ø. Sæther, S. Löfgren, P. G. Söderberg, J. Krane, and A. Midelfart, "Metabolic changes in rat lens after in vivo exposure to ultraviolet irradiation: measurements by high resolution MAS ${ }^{1} \mathrm{H}$ NMR spectroscopy," Investigative Ophthalmology and Visual Science, vol. 45, no. 6, pp. 1916-1921, 2004.

[29] O. Sæther, Ø. Risa, J. Čejková, J. Krane, and A. Midelfart, "High-resolution magic angle spinning ${ }^{1} \mathrm{H}$ NMR spectroscopy of metabolic changes in rabbit lens after treatment with dexamethasone combined with UVB exposure," Graefe's Archive for Clinical and Experimental Ophthalmology, vol. 242, no. 12, pp. 1000-1007, 2004.

[30] A. Spector, "The lens and oxidative stress," in Oxidative Stress: Oxidants and antiOxidants, H. Seis, Ed., pp. 529-586, Academic Press, London, UK, 1991.

[31] S. Zhang, Y. Zhaug, X. Liu et al., "Detection of sorbitol content in crystalline lens of normal rats and rats with diabetic cataract by H-NMR," Hua Xi Yi Ke Da Xue Xue Bao, vol. 21, no. 2, pp. 125-127, 1990.

[32] G. Ellman and H. Lysko, "A precise method for the determination of whole blood and plasma sulfhydryl groups," Analytical Biochemistry, vol. 93, no. 1, pp. 98-102, 1979. 
[33] H. Ohkawa, N. Ohishi, and K. Yagi, "Assay for lipid peroxides in animal tissues by thiobarbituric acid reaction," Analytical Biochemistry, vol. 95, no. 2, pp. 351-358, 1979.

[34] P. Kar, D. Laight, H. K. Rooprai, K. M. Shaw, and M. Cummings, "Effects of grape seed extract in Type 2 diabetic subjects at high cardiovascular risk: a double blind randomized placebo controlled trial examining metabolic markers, vascular tone, inflammation, oxidative stress and insulin sensitivity," Diabetic Medicine, vol. 26, no. 5, pp. 526-531, 2009.

[35] J. Sanderson, W. R. McLauchlan, and G. Williamson, "Quercetin inhibits hydrogen peroxide-induced oxidation of the rat lens," Free Radical Biology and Medicine, vol. 26, no. 5-6, pp. 639-645, 1999.

[36] F. J. Giblin, J. R. Reddan, L. Schrimscher, D. C. Dziedzic, and V. N. Reddy, "The relative roles of the glutathione redox cycle and catalase in the detoxification of $\mathrm{H}_{2} \mathrm{O}_{2}$ by cultured rabbit lens epithelial cells," Experimental Eye Research, vol. 50, no. 6, pp. 795-804, 1990.

[37] R. E. Reeves and P. R. Cammarata, "Osmoregulatory alterations in myo-inositol uptake by bovine lens epithelial cells-part 5: mechanism of the myo-inositol efflux pathway," Investigative Ophthalmology and Visual Science, vol. 37, no. 4, pp. 619-629, 1996.

[38] S. D. Varma, K. Hegde, and M. Henein, "Oxidative damage to mouse lens in culture. Protective effect of pyruvate," Biochimica et Biophysica Acta, vol. 1621, no. 3, pp. 246-252, 2003.

[39] I. G. Obrosova and M. J. Stevens, "Effect of dietary taurine supplementation on GSH and $\mathrm{NAD}(\mathrm{P})$-redox status, lipid peroxidation, and energy metabolism in diabetic precataractous lens," Investigative Ophthalmology and Visual Science, vol. 40, no. 3, pp. 680-688, 1999.

[40] K. P. Mitton, P. A. W. Dean, T. Dzialoszynski, H. Xiong, S. E. Sanford, and J. R. Trevithick, "Modelling cortical cataractogenesis 13. Early effects on lens ATP/ADP and glutathione in the streptozotocin rat model of the diabetic cataract," Experimental Eye Research, vol. 56, no. 2, pp. 187-198, 1993.

[41] F. Kilic, R. Bhardwaj, J. Caulfeild, and J. R. Trevithick, "Modelling cortical cataractogenesis 22: is in vitro reduction of damage in model diabetic rat cataract by taurine due to its antioxidant," Experimental Eye Research, vol. 69, no. 3, pp. 291300, 1999.

[42] K. P. Mitton, H. A. Linklater, T. Dzialoszynski, S. E. Sanford, K. Starkey, and J. R. Trevithick, "Modelling cortical cataractogenesis 21: in diabetic rat lenses taurine supplementation partially reduces damage resulting from osmotic compensation leading to osmolyte loss and antioxidant depletion," Experimental Eye Research, vol. 69, no. 3, pp. 279-289, 1999.

[43] M. J. C. Crabbe and D. Goode, "Aldose reductase: a window to the treatment of diabetic complications?" Progress in Retinal and Eye Research, vol. 17, no. 3, pp. 313-383, 1998.

[44] J. I. Malone, S. Lowitt, and W. R. Cook, "Nonosmotic diabetic cataracts," Pediatric Research, vol. 27, no. 3, pp. 293-296, 1990.

[45] P. F. Kador, Y. Akagi, and J. H. Kinoshita, "The effect of aldose reductase and its inhibition on sugar cataract formation," Metabolism, vol. 35, no. 4, pp. 15-19, 1986.

[46] J. Yamakoshi, M. Saito, S. Kataoka, and S. Tokutake, "Procyanidin-rich extract from grape seeds prevents cataract formation in hereditary cataractous (ICR/f) rats," Journal of Agricultural and Food Chemistry, vol. 50, no. 17, pp. 4983-4988, 2002.

[47] P. F. Kador, D. Betts, M. Wyman, K. Blessing, and J. Randazzo, "Effects of topical administration of an aldose reductase inhibitor on cataract formation in dogs fed a diet high in galactose," American Journal of Veterinary Research, vol. 67, no. 10, pp. 1783-1787, 2006.

[48] D. G. Raj, S. Ramakrishnan, and C. S. Devi, "Myoinositol and peroxidation - an in vitro study on human cataractous lens and human erythrocytes," Indian Journal of Biochemistry and Biophysics, vol. 32, no. 2, pp. 109-111, 1995.

[49] C. Zhou, N. Agarwal, and P. R. Cammarata, "Osmoregulatory alterations in myo-inositol uptake by bovine lens epithelial cells-part 2: cloning of a 626 bp cDNA portion of a Na+/myoinositol cotransporter, an osmotic shock protein," Investigative Ophthalmology and Visual Science, vol. 35, no. 3, pp. 1236-1242, 1994.

[50] T. Yokoyama, L.-R. Lin, B. Chakrapani, and V. N. Reddy, "Hypertonic stress increases NaK ATPase, taurine, and myoinositol in human lens and retinal pigment epithelial cultures," Investigative Ophthalmology and Visual Science, vol. 34, no. 8, pp. 25122517, 1993.

[51] R. Kumar, D. K. Patel, D. Laloo, K. Sairam, and S. Hemalatha, "Inhibitory effect of two Indian medicinal plants on aldose reductase of rat lens in vitro," Asian Pacific Journal of Tropical Medicine, vol. 4, no. 9, pp. 694-697, 2011.

[52] E. Nicolle, F. Souard, P. Faure, and A. Boumendjel, "Flavonoids as promising lead compounds in type 2 diabetes mellitus: molecules of interest and structure-activity relationship," Current Medicinal Chemistry, vol. 18, no. 17, pp. 2661-2672, 2011. 

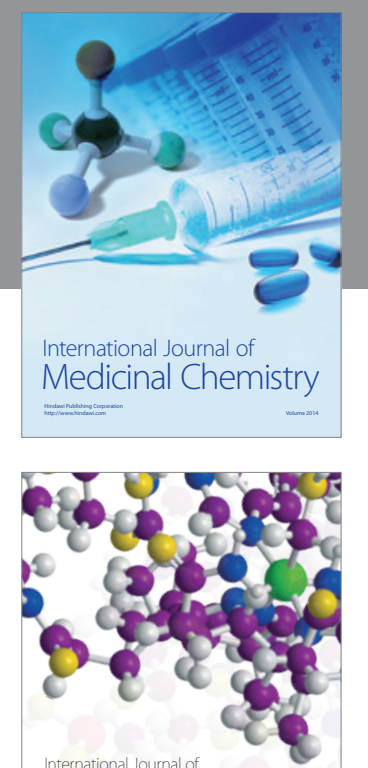

\section{Carbohydrate} Chemistry

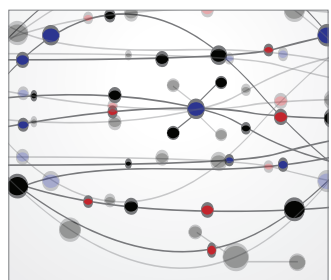

The Scientific World Journal
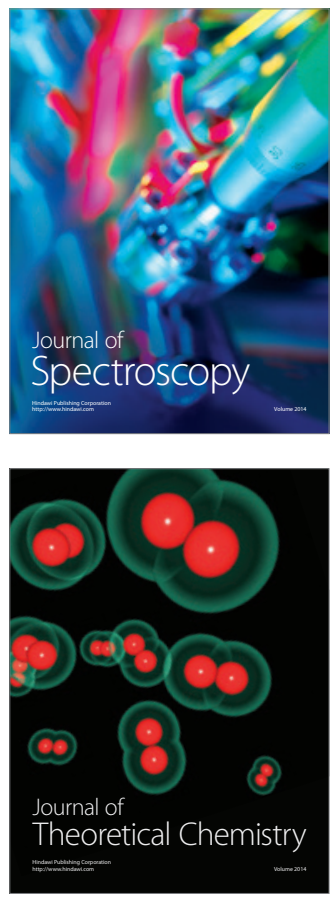
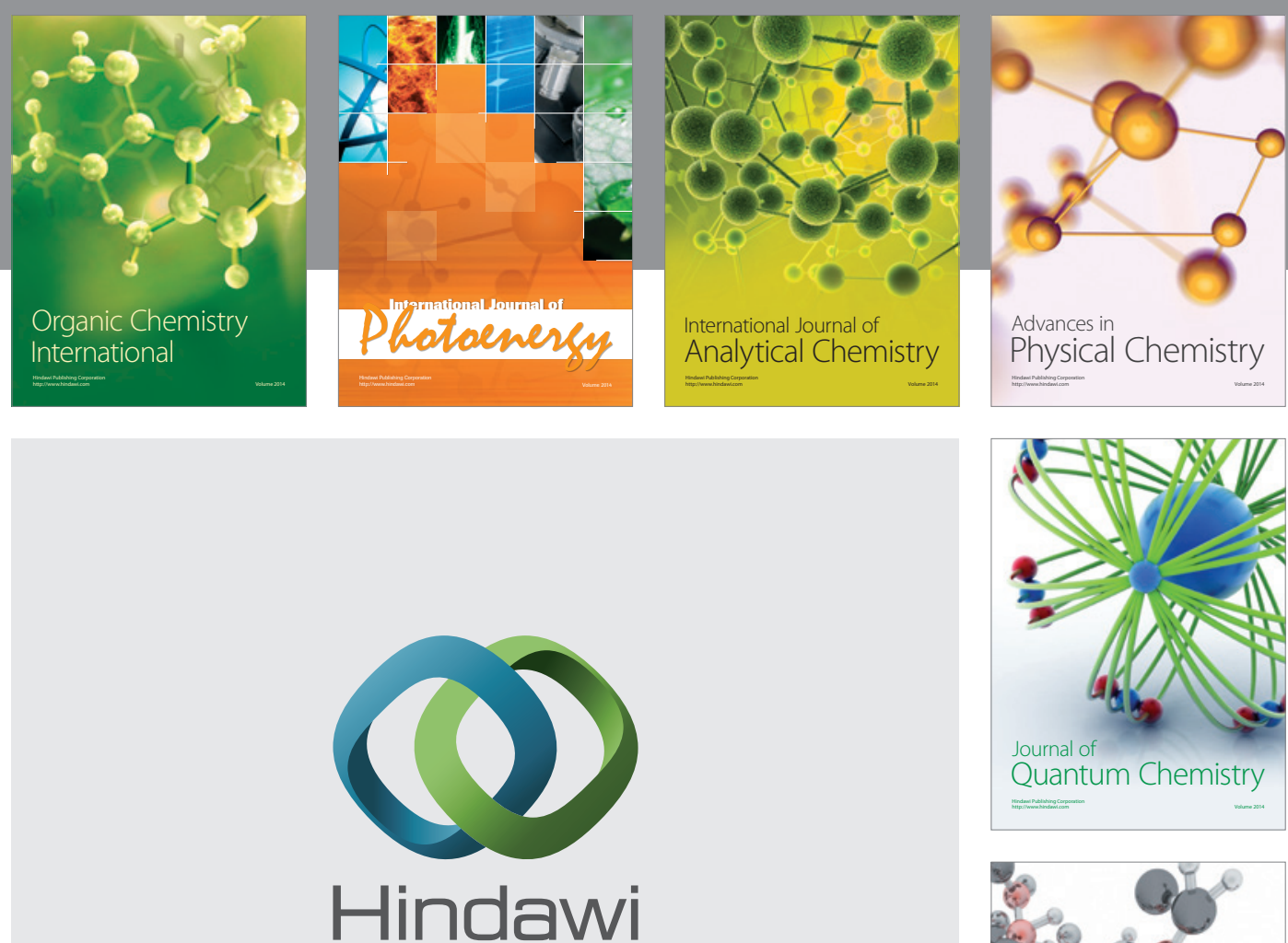

Submit your manuscripts at

http://www.hindawi.com

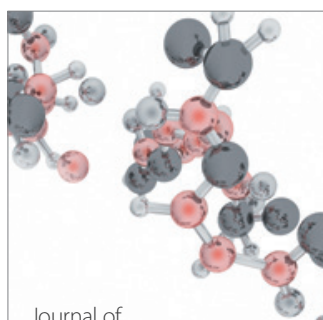

Analytical Methods

in Chemistry

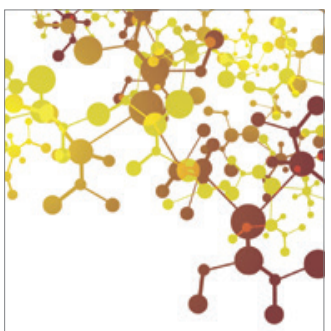

Journal of

Applied Chemistry

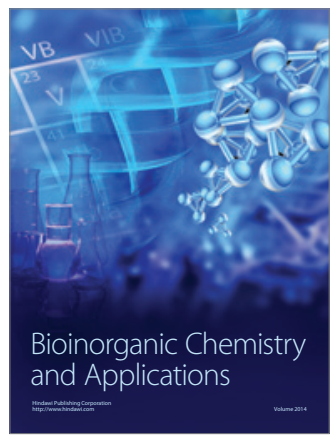

Inorganic Chemistry
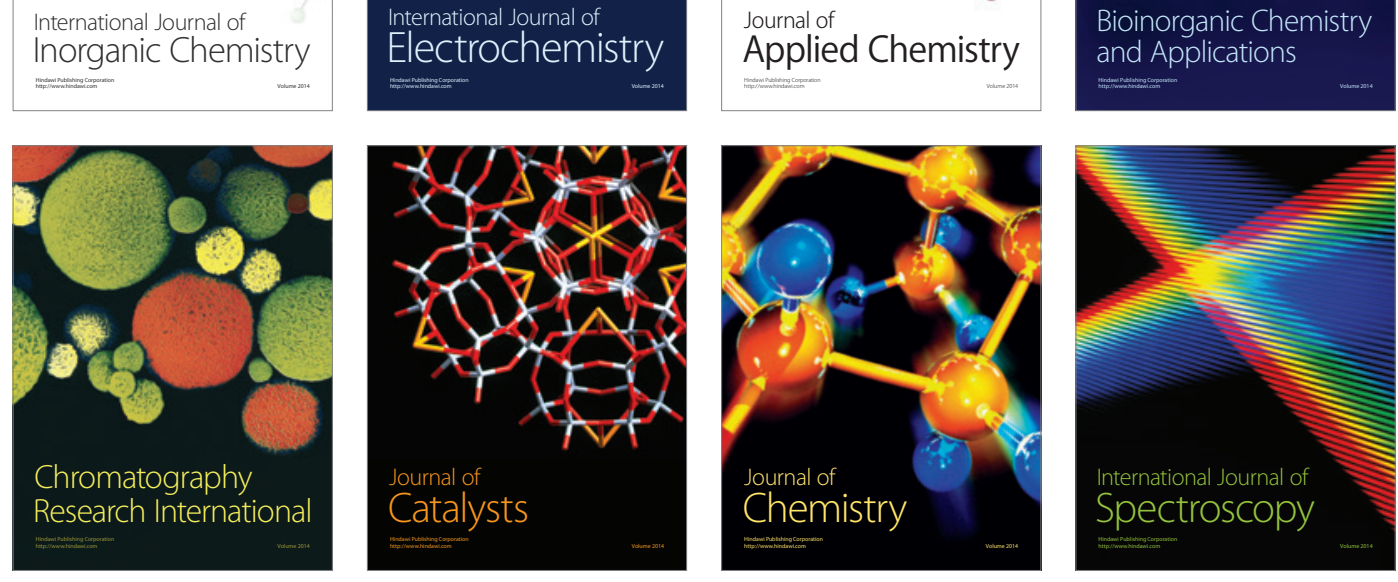